1 This is an unofficial adaptation of an article that appeared in an ACS publication. ACS has not endorsed the

2 content of this adaptation or the context of its use.

3 This document is the accepted manuscript version of the following article:

Kéri, A.; Dähn, R.; Krack, M.; Churakov, S. V. Combined XAFS spectroscopy and ab initio study on the characterization of iron incorporation by montmorillonite. Environmental Science and Technology 2017, 51(18), 10585-10594.

7 The article in the format of the journal can be downloaded from https://doi.org/10.1021/acs.est.7b01670

\title{
Combined XAFS spectroscopy and ab initio study on the characterization of iron incorporation by montmorillonite
}

\author{
Annamária Kéri ${ }^{1,2, *}$, Rainer Dähn ${ }^{1}$, Matthias Krack ${ }^{3}$, Sergey V. Churakov ${ }^{1,2}$
}

${ }^{1}$ Laboratory for Waste Management, Paul Scherrer Institute, CH-5232 Villigen PSI, Switzerland

${ }^{2}$ Institute of Geological Sciences, University of Bern, CH-3012 Bern, Switzerland

${ }^{3}$ Laboratory for Reactor Physics and Systems Behaviour, Paul Scherrer Institute, CH-5232

Villigen PSI, Switzerland

*Corresponding author. E-mail: annamaria.keri@psi.ch

Tel: +41563102368

Fax: +41563102199

\section{Abstract}

Iron occurs in clay minerals in both ferric and ferrous forms. Depending on its oxidation state and the environmental conditions, it can participate in redox reactions and influence the sorption processes at surfaces of clay minerals. Knowing the oxidation state and the preferential structural position of $\mathrm{Fe}^{2+}$ and $\mathrm{Fe}^{3+}$ is essential for the detailed understanding of the mechanism and kinetics of such processes. In this study, molecular dynamics (MD) calculations based on density functional theory $(\mathrm{DFT}+\mathrm{U})$ were applied to simulate the incorporated $\mathrm{Fe}$ in bulk montmorillonite and to explain the measured $\mathrm{Fe} \mathrm{K}$-edge X-ray absorption fine structure (XAFS) spectra. The analysis of the experimental data and simulation results suggested that iron in montmorillonite is preferentially incorporated as $\mathrm{Fe}^{3+}$ into the octahedral layer. The simulations showed that there is no preferential occupation of cis- or trans-sites by $\mathrm{Fe}^{2+}$ and $\mathrm{Fe}^{3+}$ in bulk montmorillonite. A very good agreement between the $a b$ initio simulated and measured XAFS spectra demonstrate the robustness of the employed simulation approach. 


\section{Introduction}

37 Iron is one of the most abundant redox-active element in soils and sediments ${ }^{1}$. Main phases containing ferrous and ferric iron in the sub-surface environment are oxides, hydroxides and clay minerals. Since clay minerals incorporate structural iron in both ferrous $\left(\mathrm{Fe}^{2+}\right)$ and ferric $\left(\mathrm{Fe}^{3+}\right)$ oxidation states, iron species associated with naturally occurring clay minerals are of a great relevance for bio-geochemical redox reaction, geochemical recycling of heavy metals and migration of radionuclides ${ }^{1,2-5}$. Accordingly, Fe-bearing clay minerals play a role in the main redox controlling phase in geochemical systems. They can concurrently act as electron donor for oxidative sorption of redox sensitive cations which affect e.g. the net negative charge of the mineral structure, the hydration of smectite surfaces and the cation exchange capacity of the clay mineral ${ }^{6-8}$. Wet chemistry measurements, batch sorption experiments and spectroscopy studies revealed that the adsorption of ferrous iron on clay minerals are strongly depended on the structural iron concentration and its redox state that has also an influence on the individual uptake characteristics of ferrous iron and other divalent ions when Fe-bearing clay minerals are present in the system ${ }^{3,9-11}$. The influence of the competitive sorption effects between $\mathrm{Fe}^{2+}$ and other relevant transition metals on their uptake characteristics remains an important issue ${ }^{3}$.

The structure of Fe-bearing smectites can be described as layers of pseudohexagonally ordered sheets of alumina octahedra sandwiched between two opposing tetrahedral siloxane sheets ${ }^{12} . \mathrm{Fe}^{2+}$ and $\mathrm{Fe}^{3+}$ mainly substitutes in the $\mathrm{Al}$ octahedral sheet while minor quantities of $\mathrm{Fe}^{3+}$ can substitute for $\mathrm{Si}$ in the tetrahedral sheet. One third of the octahedral sites are transsymmetric and two thirds of the octahedral sites are cis-symmetric with respect to the orientation of the hydroxyl $\left(\mathrm{OH}^{-}\right)$groups ${ }^{12,13}$. Most of the Fe-bearing clay minerals belong to 2:1 type of dioctahedral smectites in which only two thirds of the possible octahedral positions are occupied ${ }^{12}$. Ferric and ferrous iron can occupy both the cis- and trans-sites.

A discussion about how iron is distributed between the cis- and trans- octahedral sites in 2:1 dioctahedral smectites has been going on for many years. It has been demonstrated that iron distribution in the octahedral and in the tetrahedral layer strongly depends on the total $\mathrm{Fe}$ content $^{14}$. A general conclusion by Stucki ${ }^{15}$ based on a variety of spectroscopic and structural measurements including Mössbauer and infrared spectroscopy ${ }^{16}$ is that with increasing ironcontent in the octahedral layer, the more vacant trans-sites are, and conversely, iron-poor clay minerals exhibit with populated trans-sites. The structure of the dioctahedral Fe-rich endmember, nontronite is well-studied and the relative distribution in the octahedral layer of 
many cations (e.g. $\mathrm{Fe}^{3+}, \mathrm{Mg}^{2+}$ ) is quantified ${ }^{5,17}$. It has also been demonstrated that the structurally incorporated iron takes place in the oxidative adsorption of transition metals that can be reversible or irreversible depending on the alterations in the lattice structure of the smectite $^{8,17}$. Much less is known about iron distribution in low ( 2-3\%) Fe-bearing montmorillonites, such as Milos- and Wyoming-montmorillonite. According to Stucki ${ }^{15}$, the preferred occupational site should nearly equally be distributed among the cis-and trans-sites but the quantification is still lacking ${ }^{18}$.

The oxidation and the reduction of structural octahedral iron has been shown to be reversible in a wide range of redox conditions. Recent experimental observations demonstrated that the reversible reduction and oxidation of Fe-rich and Fe-poor clays occurs at different redox potentials ${ }^{19,21}$. Whereas nearly $100 \%$ oxidation and reduction efficiency is achieved for Fepoor montmorillonite, a noticeable amount of iron remain redox inactive ${ }^{19}$. Electrochemical and spectroscopic analysis of the reduction and the re-oxidation cycles performed with the different Fe-bearing smectites suggested that irreversible structural changes take place in the clay structure during the first reduction or oxidation cycle ${ }^{20}$.

Despite the large body of existing experimental work investigating the redox properties of structurally incorporated iron in clay mineral lattices, the molecular-level description is still lacking because the quantitative characterization of $\mathrm{Fe}^{2+}$ and $\mathrm{Fe}^{3+}$ in different structural position of the clay minerals remains challenging. The origin of the difficulties is twofolds. (1) X-ray adsorption fine structure (XAFS) and Mössbauer-spectroscopy are the two most widely applied tools for the spectroscopic identification of structural Fe incorporation in clay minerals $3,9,20,21,22$. The data analysis is often based on reference spectra for $\mathrm{Fe}^{2+}$ and $\mathrm{Fe}^{3+}$ endmembers, which, however, may represent $\mathrm{Fe}$ in a mixed structural state. (2) Iron can unequally be distributed between cis- and trans-octahedral sites which can barely or not at all be distinguished by these spectroscopic methods ${ }^{21,22}$.

Significant advances in the theoretical description of the XAFS spectra made it possible to perform theoretical prediction of extended X-ray absorption fine structure (EXAFS) and Xray absorption near edge structure (XANES) based on atomistic scale ab initio simulations. We have recently demonstrated that the combination of EXAFS spectroscopy and $a b$ initio calculations allows a quantitative description of metal-uptake by clay minerals at the atomistic level $^{23}$. A similar approach was applied to investigate speciation of arsenic ${ }^{24,25}$ and silver ${ }^{26}$ proving the applicability of this method. Studies performed on scandium and on $\mathrm{UO}_{2}$ confirmed the successful application of the method to systems containing elements with delocalized $f$ - and $d$-electrons which are known to be challenging for ab initio simulations ${ }^{27,28}$. 
103 Whereas the modelling of the EXAFS spectra has nearly become a routine, the theoretical

104 simulation of XANES spectra for complex systems is still rare. Recent advances of the theory 105 and computational algorithms, made it possible to obtain accurate XANES spectrum of a 106 given structure on the basis of the exact curve-wave theory ${ }^{29}$.

107 In this study, we demonstrate that it is possible to obtain a consistent quantitative 108 interpretation of the measured EXAFS and XANES spectra using linear combination fit of 109 spectra obtained from atomistic simulations. To this end, we obtained a set of $a b$ initio 110 molecular dynamic trajectories of Fe-bearing montmorillonite with different structural 111 location of ferrous and ferric iron. We further performed a sensitivity analysis of the 112 theoretical model parameters for the XAFS spectra simulations to evaluate the effects of the 113 changing in the structural environment and the Fe oxidation state on the spectra. Comparing 114 the modelling results and the experimental observations, we gained insights into the structural 115 environment of iron. To the best of our knowledge, this is the first complete theoretical 116 evaluation of Fe K-edge XAFS modeling performed on a Fe-bearing clay mineral system.

\section{2. Materials and methods}

\section{$118 \quad$ 2.1. Modeling setup}

119 In our study, we considered idealized defect free tetrahedra-octahedra-tetrahedra (TOT) 120 frames of a 2:1 dioctahedral clay with the general formula of $\left(4 x\left[\mathrm{Al}_{8} \mathrm{Si}_{16} \mathrm{O}_{40}(\mathrm{OH})_{8}\right]\right)$. It is 121 often used as the simplest structural prototype for dioctahedral clays. The simulations were performed on a single clay particle without water in the interlayer. The dimensions of the orthorhombic supercell were $(18.2 \times 20.8 \times 15.0) \AA$. Similar to the previous work ${ }^{23,30}$, the cell parameter in the " $c$ " direction was fixed at $15 \AA$ to minimize the interaction between the periodic images ${ }^{31,32}$. The incorporation of ferrous and ferric iron in the structure was

126 considered as an exchange with the alumina in cis- and trans-octahedral position (Figure 1), 127 respectively ${ }^{33}$. 

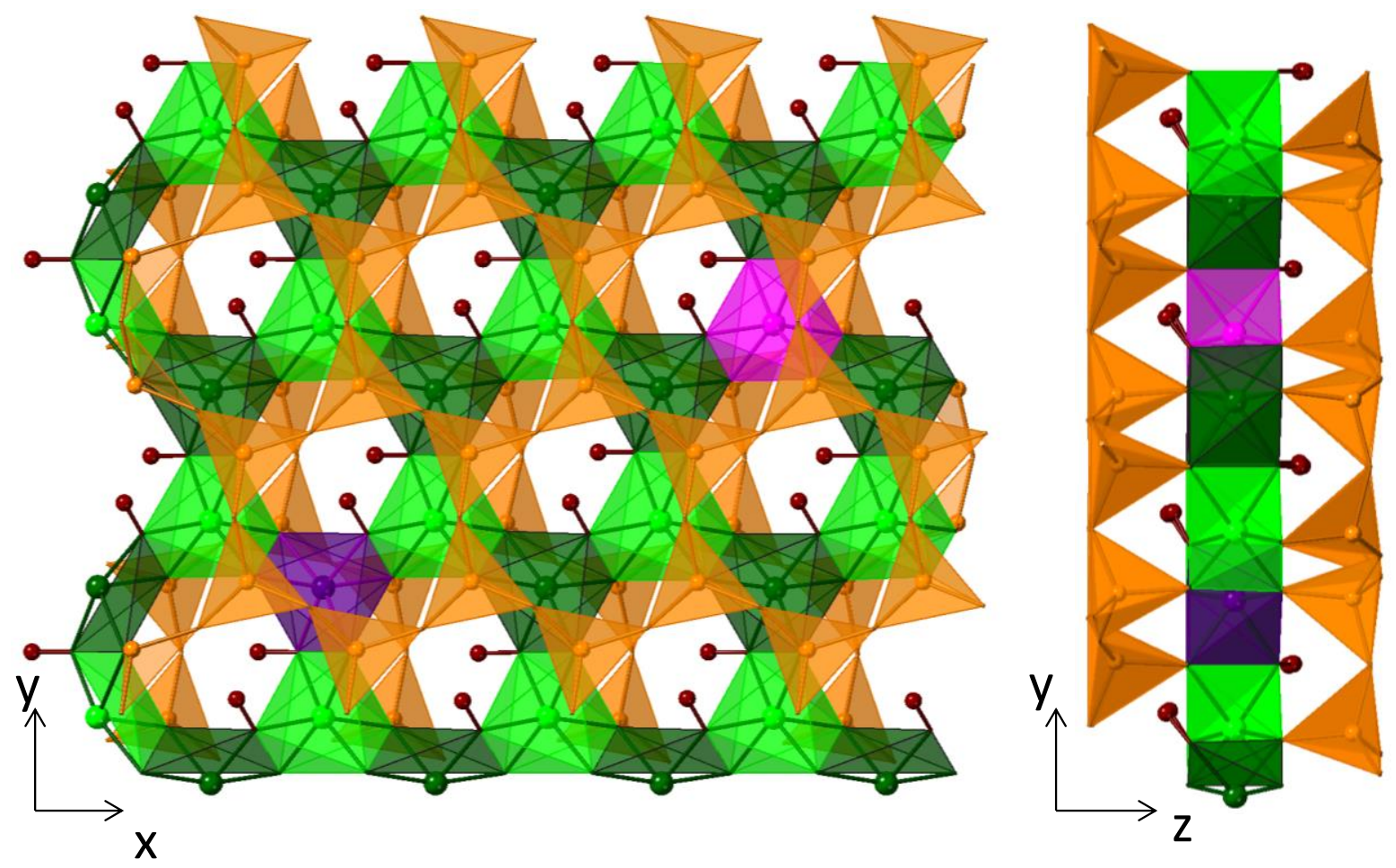

Figure 1. Views of the modeled montmorillonite with substituted iron at the cis- and transsites of the octahedra. The structural incorporation of $\mathrm{Fe}$ is illustrated as pink (magenta) octahedron at the cis-site and dark purple octahedral at the trans-site. The cis- and trans-site substitution can be distinguished by the different relative position of hydroxyl $\left(\mathrm{OH}^{-}\right)$groups shown with red spheres. Alumina octahedra are shown in green while silica tetrahedra are orange.

\subsection{Ab initio calculations}

The spin polarized electronic structure calculations were performed based on the density functional theory (DFT) using the Gaussian Plane Wave (GPW) method as it is implemented

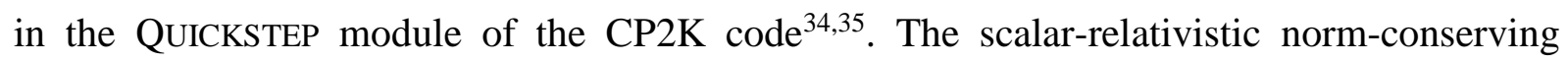
pseudopotentials of Goedecker, Teter and Hutter $(\mathrm{GTH}){ }^{36},{ }^{37}$ were applied to avoid the explicit consideration of the core electrons (for iron $[\mathrm{Ne}] 3 \mathrm{~s}^{2} 3 \mathrm{p}^{6} 4 \mathrm{~s}^{2} 3 \mathrm{~d}^{6}$ ). The wave functions of valence electrons were described by a linear combination of contracted Gaussian-type orbitals using MOLOPT basis sets optimized for the corresponding GTH pseudopotentials ${ }^{38}$. An auxiliary basis set of plane waves was employed to expand the electronic density using an electronic density cutoff of 1500 Ry for the electronic density of states calculation and $400 \mathrm{Ry}$ for molecular dynamics simulations. The exchange and correlation energy was calculated using the exchange-correlation functional of Perdew, Burke and Ernzerhof (PBE) ${ }^{39,40}$. The simulations were performed with a multiplicity $(2 S+1)_{\mathrm{Fe}^{2+}}=5$ for systems with a ferrous iron and $(2 S+1)_{F^{3+}}=6$ for systems with a ferric iron, respectively. 
149 Conventional DFT is known to underestimate the Coulomb repulsion between the localized $1503 d$-electrons of $\mathrm{Fe}^{41}$. In order to obtain a more accurate description of these states, the socalled DFT+U method was applied ${ }^{42,43}$. In this semi empirical approach, an additional potential is applied on the selected $3 d$-states of $\mathrm{Fe}$ (for more details see Supporting Information 1).

154 Born-Oppenheimer molecular dynamics (MD) simulations using a $\Gamma$-point sampling were 155 performed within the canonical ensemble (NVT) controlled by a stochastic thermostat ${ }^{44}$ 156 employing an MD time step of $0.5 \mathrm{fs}$. In each time step, the energy was converged to $1576.3 \times 10^{-5} \mathrm{kcal} /$ atom. In this way, four $20 \mathrm{ps}$ long ab initio MD trajectories of montmorillonite with structural $\mathrm{Fe}^{2+}$ and $\mathrm{Fe}^{3+}$ present in trans- and cis-position were obtained which were used to calculate thermal averaged XAFS spectra of the Fe-bearing montmorillonite.

\subsection{Calculations of EXAFS and XANES spectra}

161 The EXAFS spectra were calculated based on molecular configurations derived from the $a b$ initio simulations using the FEFF 8.40 software $^{45,46}$. For each atomic configuration, the scattering potential of the atoms were calculated self-consistently ${ }^{45,47}$. The amplitude reduction factor $\left(S_{0}^{2}\right)$ was set to 1.0. Multiscattering paths up to eight legs with path lengths up to $7.0 \AA$ were taken into account. The radius of the cluster for self-consistent full multiple scattering calculations was set to $5.0 \AA$.

The thermal disorder was taken into account in two ways. In the first case, 320 molecular snapshots from MD trajectories at $300 \mathrm{~K}$ simulating temperature separated by a $50 \mathrm{fs}$ time step were averaged. Here, the thermal motion of the atoms were "directly" considered. In the second "indirect" case, the static configurations derived from the initially relaxed structures were used with a Debye-Waller factor of 0.006 in the EXAFS calculations. Other parameters were set to the default values ${ }^{46,48}$.

173 The calculated EXAFS spectra served as the basis for the interpretation of the experimental 174 data. The linear combination fit to the experimental EXAFS spectra was performed according 175 to Eq. 1 after max-min normalization to the value of the first oscillation of the calculated and 176 the measured spectra ${ }^{23}$.

$$
Q=\left\|k^{3}\left[\sum_{i}\left(a_{i}^{2} \chi_{i}(k)\right)-\chi^{\exp }(k)\right]\right\|^{2}+\left\|a_{i}^{2}\right\|^{2}
$$

178 where $\langle\chi(k)\rangle_{i}$ are the calculated and $\chi^{\exp }(k)$ is the experimental EXAFS spectra, $a_{i}^{2}$ are the 179 fitting parameters for the four different types of montmorillonite structures. The fitting was 180 limited to the interval of $k\left(\AA^{-1}\right) \in[3.0,9.0]$. 
181 The theoretical prediction of XANES spectra is very challenging because of the complexity of 182 the underlying equations which can only be solved in an approximate way. The aim of this study was (1) to demonstrate that the quantitative approach used for the interpretation of

184 EXAFS spectra is also applicable to XANES spectra; (2) to determine the preferred oxidation state and occupational site of iron with two independent methods. The XANES spectra were calculated on the basis of two different theoretical approaches. The first set of the XANES spectra was obtained using the self-consistent real space multiple scattering (RSMS) method implemented in the FEFF 8.40 code. The second set of XANES spectra was obtained using the fully relativistic density functional theory with the local spin-density approximation (DFTLSDA) code FDMNES ${ }^{49}$. We calculated the spectra for $6.0 \AA$ large molecular clusters derived from the $a b$ initio geometry optimization and MD simulations. The scattering potentials of the atoms were calculated self-consistently $(\mathrm{SCF})$ for each atomic configuration. For the structures obtained by geometry optimization, the XANES spectra were obtained by convolution of electronic DOS with an arctangent weighted Lorentzian as it is defined in the FDMNES software ${ }^{49-51}$. Other parameters were set to the default values ${ }^{52}$. (More detailed information about the FDMNES parameter choice can be found in the Supporting Information 2.) For the data from MD simulations, well-converged XANES spectra were obtained convolving 100 instantaneous snapshots (separated by $160 \mathrm{fs}$ each).

The calculated XANES spectra also served as the basis for the interpretation of the experimental data after max-min normalization. The fit to the experimental XANES spectra was performed according to Eq. 2, which is conceptually similar to Eq. 1.

$$
Q=\left\|\sum_{i}\left(b_{i}^{2} \mu_{i}(E)\right)-\mu^{e x p}(E)\right\|^{2}+\left\|b_{i}^{2}\right\|^{2}
$$

203

204

where $\mu_{i}(E)$ are the calculated and $\mu^{\exp }(E)$ is the experimental XANES spectra, $b_{i}^{2}$ are the fitting parameters for the four different type of montmorillonite structures. The fitting was limited to the interval of $E(\mathrm{eV}) \in[7110,7200]$ (the Fe K-edge is $7112 \mathrm{eV}$ ).

The Euclidian norm was used during the fittings as defined by the scalar product. The fit was accepted when the spectra features in the XAFS signal matched and the $Q$ values (indicators for the fit quality) were the lowest for the given $a_{i}^{2}$ and $b_{i}^{2}$ values, respectively.

\subsection{XAFS experiments}

Two type of low Fe-bearing montmorillonite samples were used which show similar diversity of octahedral crystal chemistry ${ }^{53}$. A Milos- (Mil) and a Wyoming-montmorillonite (SWy) sample was prepared from the "as received" material without any physical or chemical 
213 treatment by pressing a pellet. The Fe K-edge XAFS spectra were collected at the Stanford 214 Synchrotron Radiation Lightsource (SSRL, Menlo Park, CA) at the beamline 11-2 using a $215 \mathrm{Si}(220)$ double crystal monochromator and a Canberra 100-pixel Ge solid-state monolith 216 detector. Higher order harmonics were rejected by detuning the monochromator by $30 \%$. The 217 monochromator angle was calibrated at the Fe K-edge by assigning the energy of $7112 \mathrm{eV}$ to 218 the first inflection point of the K-edge absorption spectrum of Fe metal foil. XAFS data 219 reduction was performed with the Athena/Artemis interface of the IFEFFIT software ${ }^{54,55}$ 220 following standard procedures ${ }^{56,57}$.

\section{3. Results and Discussion}

\subsection{EXAFS spectra}

223 The calculated Fe K-edge EXAFS spectra for montmorillonite with $\mathrm{Fe}^{2+}$ and $\mathrm{Fe}^{3+}$ located in 224 the cis- and trans-occupational sites were obtained and compared with experimental 225 spectrum. The statistical and thermal disorder was first taken into account directly as the MD 226 trajectories modeled at $300 \mathrm{~K}$ temperature served as the basis for the spectroscopic 227 calculations (Figure 2a). In the second case, when the relaxed atomic structures at $0 \mathrm{~K}$ were 228 the basis for the EXAFS calculations, a global Debye-Waller factor was applied in the spectroscopic studies (Figure 2b). Although, the MD based EXAFS spectra were broadened,

230 the spectra obtained from the relaxed geometries and the MD trajectories agree very well 231 (Figure 2a,b).

232 The calculated spectra for $\mathrm{Fe}^{2+}$ and $\mathrm{Fe}^{3+}$ are clearly different in both cases. The first difference 233 between the spectra with distinct iron ionic state is a slight shift in the first oscillation at $234 k \sim 4.3 / 4.5 \AA^{-1}$. A double-bounced oscillation at $k \sim 6.1 / 6.6 \AA^{-1}$ was present only for the 235 structures containing ferric iron. Differences could also be seen at the third oscillation $236\left(k \sim 7.7 / 8.4 \AA^{-1}\right)$ where the shoulders were at the opposite side (left for $\mathrm{Fe}^{2+}$ and right for $237 \mathrm{Fe}^{3+}$ ). On the other hand, iron in the cis- or trans-coordination (light and dark lines on 238 Figure 2a,b) turned out to have a minor effect on the obtained spectra.

239 The spectra of the Milos- and Wyoming-montmorillonite samples were similar, the only 240 difference appeared at the double-bounced oscillation at $k \sim 6.1 / 6.6 \AA^{-1}$. The second 241 oscillation for the SWy sample was higher. 

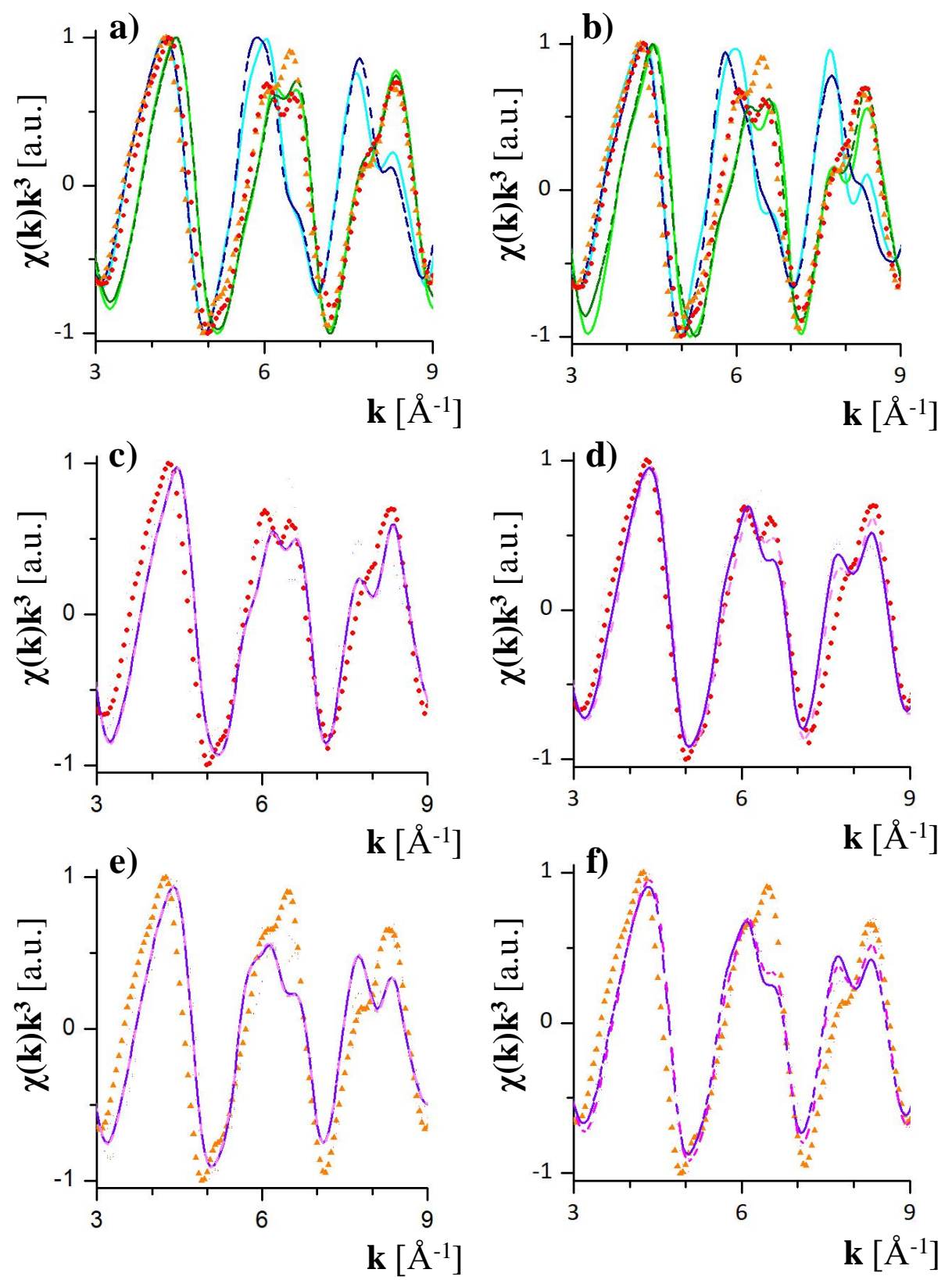

243 Figure 2. Experimental EXAFS spectra (red circles for Milos- and orange triangle for SWy244 montmorillonite) of montmorillonite with iron incorporation and modeled EXAFS spectra 245 (lines) of $\mathrm{Fe}$ incorporated in the octahedral layer of 2:1 clay. In panels a and b, blue colors 246 correspond to the incorporated ferrous iron $\left(\mathrm{Fe}^{2+}\right)$, while green colors represent incorporated 247 ferric iron $\left(\mathrm{Fe}^{3+}\right)$. The lines with lighter color represent the iron at the cis-site, while dashed 248 darker lines correspond to the trans-occupational site. In panels $\mathrm{c}-\mathrm{f}$, the lines represent the 249 linear combination fits, the darker purple lines show "Fit 1", while the dashed lighter pink 250 lines correspond to the "Fit 2". Panels c and d represent fits to the Milos- montmorillointe 251 spectra with contributions determined in Table 1, while panels e and $\mathrm{f}$ show linear 252 combination fits for SWy-montmorillonite spectra with contributions determined in Table 2. 253 The calculated EXAFS spectra for panels a, c, and e were derived from MD simulations, 254 while in panels $\mathrm{b}, \mathrm{d}$, and $\mathrm{f}$, the relaxed structures served as a basis. 
255 The qualitative comparison of the calculated EXAFS spectra and the experimental ones 256 indicate that the iron is present mainly in the $\mathrm{Fe}^{3+}$ form in both Milos- and Wyoming257 montmorillonite. Several linear combination fits of the measured Milos- and Wyoming258 montmorillonite spectra based on the theoretical one for the $\mathrm{Fe}_{\text {Cis }}^{2+}, \mathrm{Fe}_{\text {Trans }}^{2+}, \mathrm{Fe}_{\text {Cis }}^{3+}$ and $259 \mathrm{Fe}_{\text {Trans }}^{3+}$ were performed, in order to obtain a quantitative estimation of the preferential 260 occupational sites and the iron oxidation state. The best linear combination fits ("Fit 1" in 261 Table 1 and 2) obtained based on the MD trajectories and the relaxed structures are compared 262 with the experimental data in Figure 2c-f. The best agreement ("Fit 1") could be obtained for 263 weighted spectra containing of $\mathrm{Fe}^{2+}(30-40 \%)$ and $\mathrm{Fe}^{3+}(60-70 \%)$. Iron was found to be 264 preferentially in ferric form in both Milos- and Wyoming-montmorillonite that agreed with 265 the assumption of earlier studies ${ }^{9,53,58}$. The differences in the quality of the fits between the 266 Milos- and Wyoming-montmorillonite can be explained by the different distribution of the Fe 267 atoms in the structure. The $\mathrm{Fe}^{3+}$ atoms are randomly distributed in Milos-montmorillonite, 268 while Wyoming-montmorillonite displays an ordered iron distribution ${ }^{53}$. The simulations 269 were performed at low Fe concentration without considering iron-iron clustering. The iron270 iron clustering is believed to be responsible for the double-bounced oscillation at $k \sim 6.1$ / $2716.6 \AA^{-1}$, therefore could not be reproduced with the applied structural model.

272 The spectra of $\mathrm{Fe}_{\text {Cis }}^{2+}$ and $F e_{\text {Trans }}^{2+}$ as well as the spectra of $\mathrm{Fe}_{\text {Cis }}^{3+}$ and $\mathrm{Fe}_{\text {Trans }}^{3+}$ show only 273 slight differences, thus a second linear combination fit ("Fit 2") was performed on the 274 calculated structures. In this case, the total contributions of the $\mathrm{Fe}^{2+}$ and $\mathrm{Fe}^{3+}$ were kept the 275 same, but the contributions of the different occupational sites were equalized (Table 1 and 2). 276 The comparison of the fitting quality (Table 1 and 2) in and the fitted curves (Figure 2c-f) 277 revealed that there were only small differences between the two fits. Therefore, the 278 preferential occupation of cis- or trans-sites by $\mathrm{Fe}^{2+}$ and $\mathrm{Fe}^{3+}$ in montmorillonite could not be 279 determined by only comparing the calculated and the measured EXAFS spectra. 
280 Table 1. Parameters (contributions and quality $\left(Q_{M i l}\right)$ ) of the EXAFS and XANES linear 281 combination fit of incorporated iron with distinct oxidation state $\left(\mathrm{Fe}^{2+} / \mathrm{Fe}^{3+}\right)$ at different 282 occupational site (cis/trans) for Milos-montmorillonite, respectively ${ }^{\mathrm{a}}$.

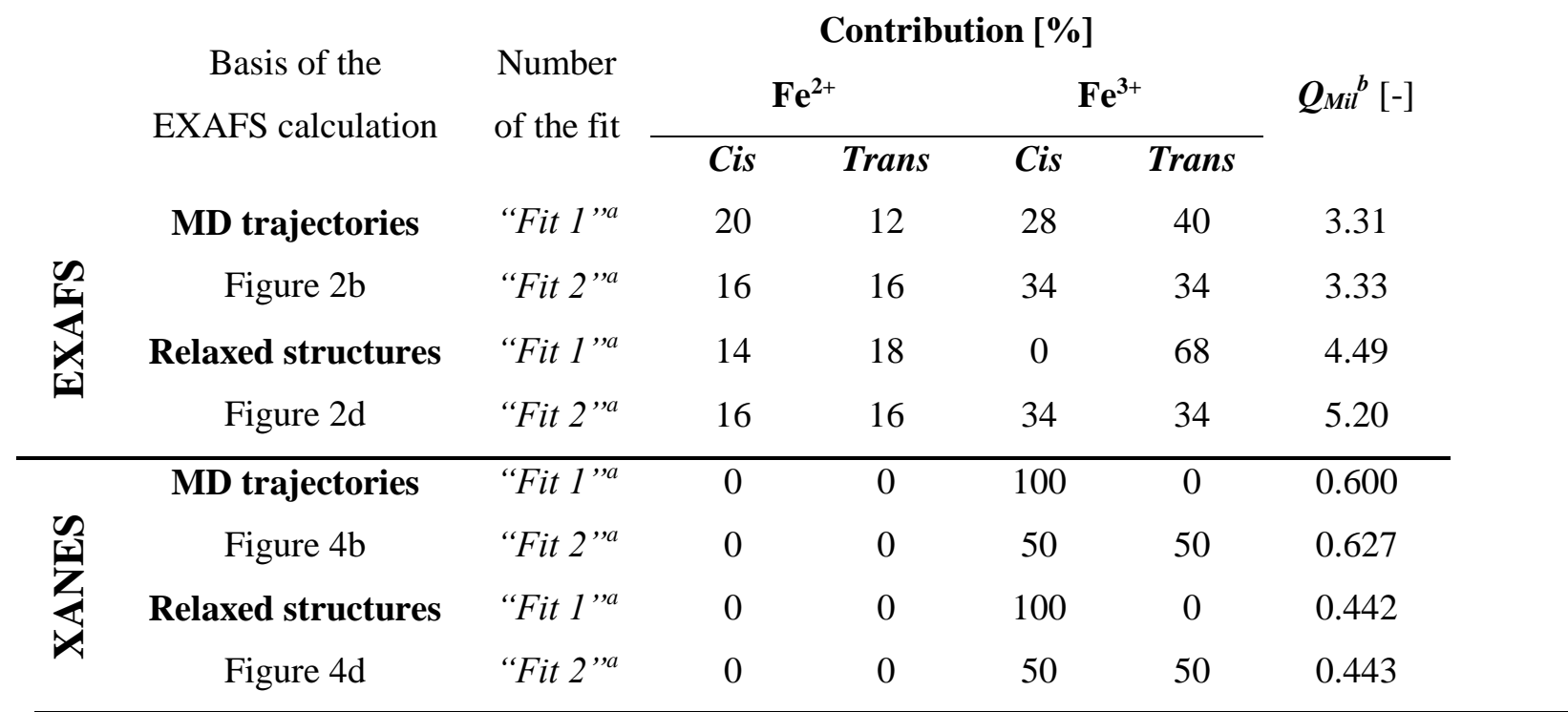

a"Fit l" corresponds to the "best fit", while "Fit 2" is the constrained "equal site distribution fit". ${ }^{b} \mathrm{Q}_{\text {Mil }}$ is calculated using Eq. 1 for EXAFS and Eq. 2 for XANES.

283 Table 2. Parameters (contributions and quality $\left(Q_{s w y}\right)$ ) of the EXAFS and XANES linear 284 combination fit of incorporated iron with distinct oxidation state $\left(\mathrm{Fe}^{2+} / \mathrm{Fe}^{3+}\right)$ at different 285 occupational site (cis/trans) for SWy-montmorillonite, respectively ${ }^{\mathrm{a}}$.

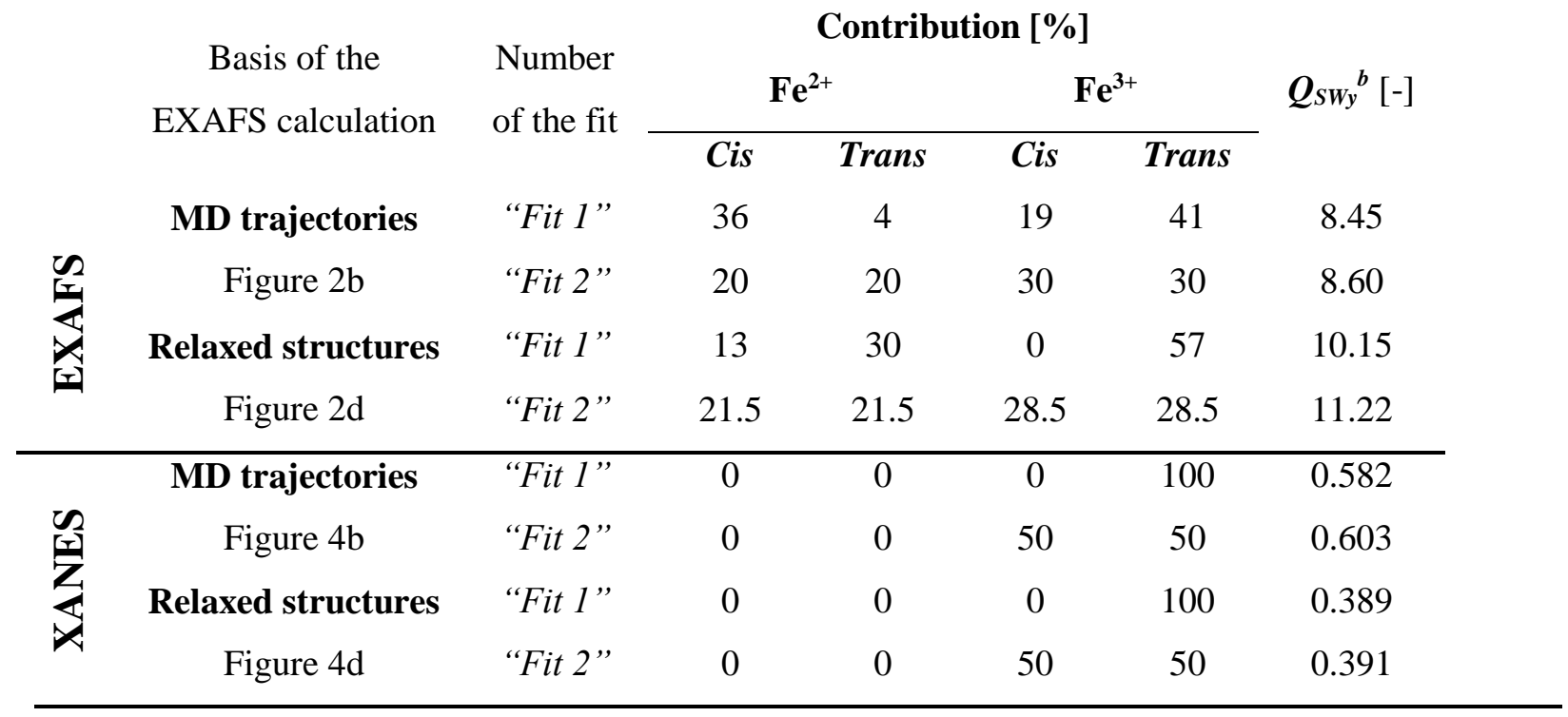

a"Fit 1" corresponds to the "best fit", while "Fit 2" is the constrained "equal site distribution fit".

${ }^{\mathrm{b}} \mathrm{Q}_{\mathrm{swy}}$ is calculated using Eq. 1 for EXAFS and Eq. 2 for XANES. 

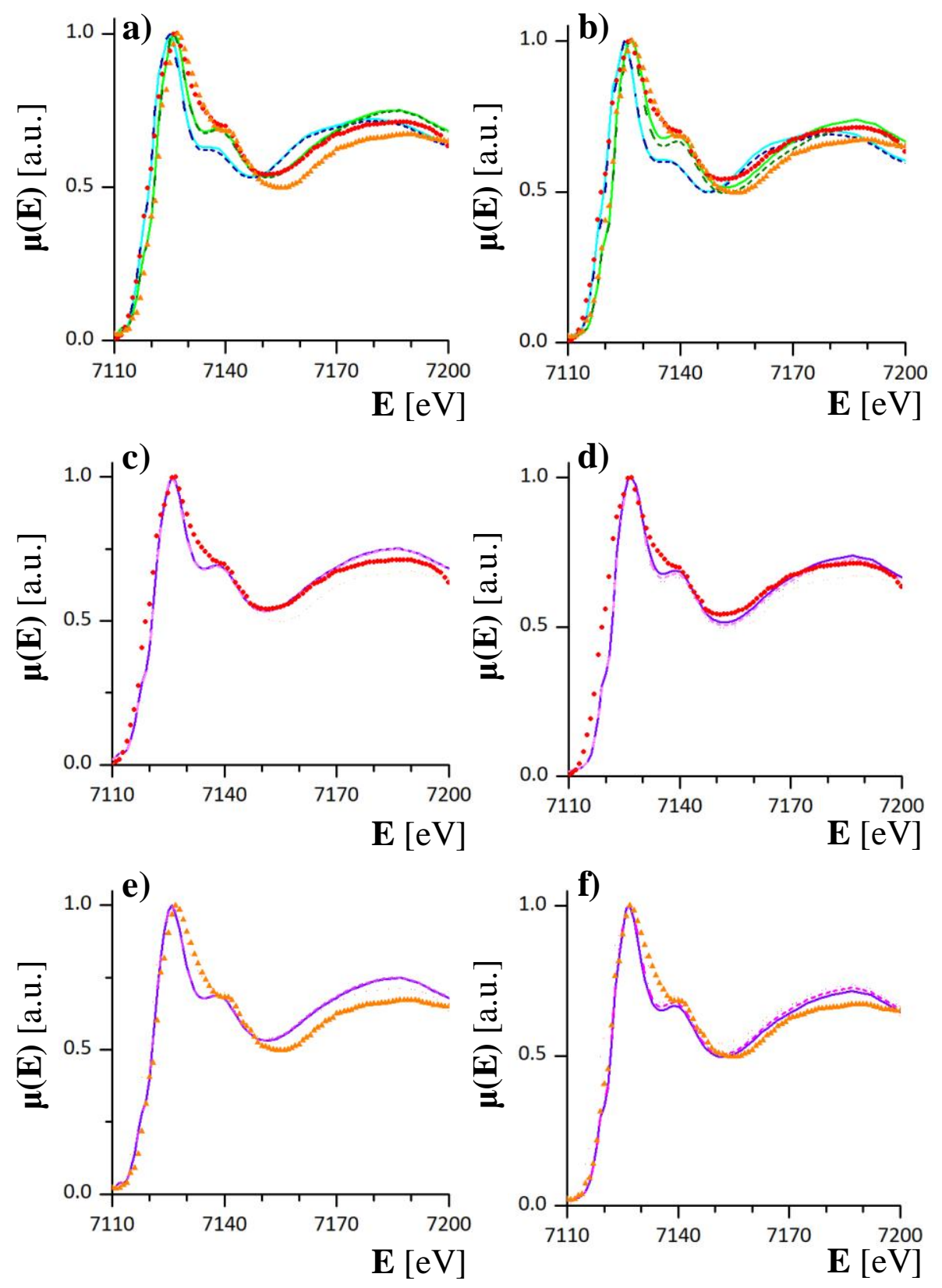

Figure 4. Experimental XANES spectra (red circles for Milos- and orange triangle for SWymontmorillonite) of montmorillonite with iron incorporation and modeled XANES spectra (lines) of Fe incorporated in the octahedral layer of 2:1 clay. In panels a and b, blue colors correspond to the incorporated ferrous iron $(\mathrm{Fe} 2+)$, while green colors represent incorporated ferric iron $(\mathrm{Fe} 3+)$. The lines with lighter color represent the iron at the cis-site while dashed

292 darker lines correspond to the trans-occupational site. In panels $\mathrm{c}-\mathrm{f}$, the lines represent the 293 linear combination fits, the darker purple lines show Fit 1, while the dashed lighter pink lines 294 correspond to the Fit 2. Panels c and d represent fits to the Milos-montmorillointe spectra with contributions determined in Table 1, while panels e and f show linear combination fit for SWy-montmorillonite spectra with contributions determined in Table 2. The calculated 297 XANES spectra for panels a, c, and e were derived from MD simulations, while for panels b, $\mathrm{d}$, and $\mathrm{f}$, the relaxed structures served as a basis. 


\subsection{XANES spectra}

300 Fe K-edge XANES spectra based on the RSMS approach for montmorillonite with $\mathrm{Fe}^{2+}$ and $301 \mathrm{Fe}^{3+}$ located in the cis- and trans-occupational sites were obtained and compared with the 302 experimental spectrum (Figure 3). At a first glance, the simulation and the measurement 303 results seem to agree, the characteristic shoulder at about $7140 \mathrm{eV}$ of the main peak is over 304 predicted (Figure 3). A more clear difference can be seen in the pre-edge region where the 305 experimental spectrum shows only a smooth shoulder but the RSMS calculations predict 306 sharp pre-edges.

307

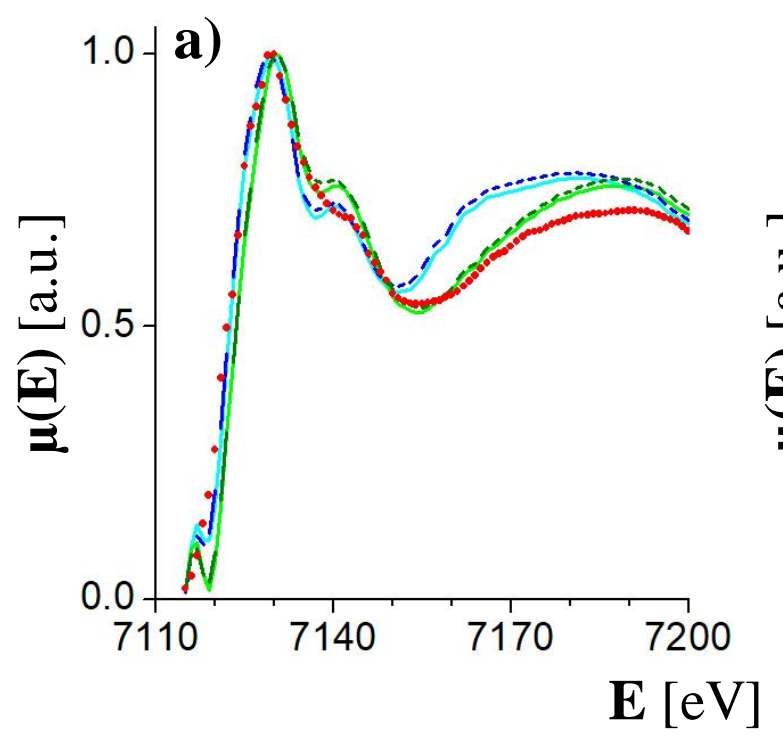

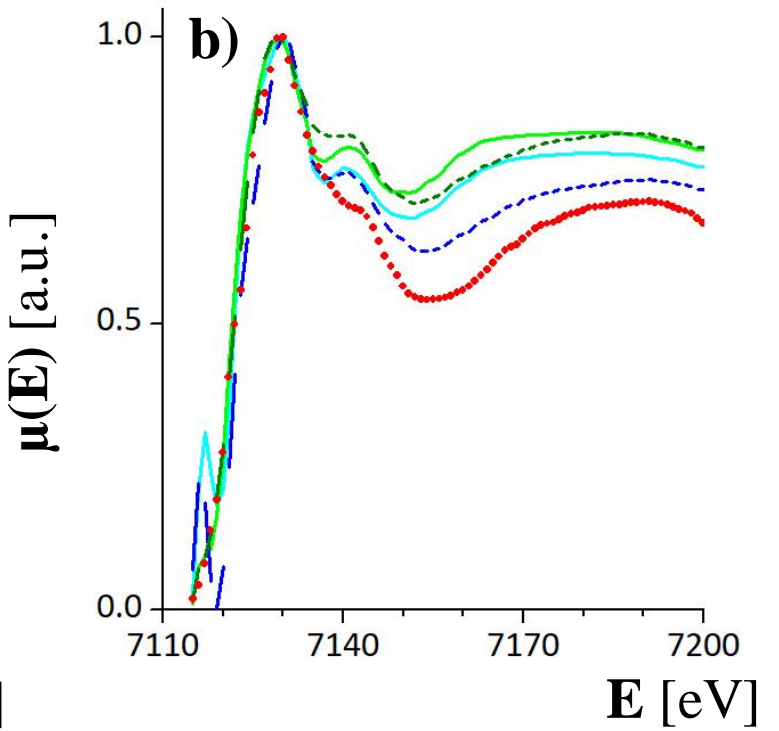

Figure 3. Experimental XANES spectra (red circles) of montmorillonite with iron incorporation and $a b$ initio XANES spectra (lines) of Fe incorporated in the octahedral layer of 2:1 clay applying FEFF 8.40 software. Blue colors correspond to the incorporated ferrous iron $\left(\mathrm{Fe}^{2+}\right)$ while green colors represent incorporated ferric iron $\left(\mathrm{Fe}^{3+}\right)$. The lighter straight lines represent the $\mathrm{Fe}$ at the cis-site while dashed darker lines correspond to the transoccupational site. The XANES spectra for $a$ ) were derived from the relaxed structures while for $b$ ) the MD simulations served as a basis.

The contradictions in the XANES spectra obtained with FEFF 8.40 software suggest that another, more sophisticated theoretical method should be applied. Therefore, we also calculated the XANES spectra based on the fully relativistic DFT-LSDA method for the four different structures with relaxed geometries using the FDMNES software ${ }^{49}$. The calculated spectra agreed well with both the measured XANES of the Milos- and the SWymontmorillonite samples, however, the spectra obtained for $\mathrm{Fe}^{2+}$ and $\mathrm{Fe}^{3+}$ are clearly different (Figure $4 \mathrm{a}, \mathrm{b}$ ). The shape of the first edge of the XANES spectra for $\mathrm{Fe}^{2+}$ and $\mathrm{Fe}^{3+}$ are very 
similar, only a small energy shift $(1-2 \mathrm{eV})$ can be recognized. The height of the characteristic shoulder at about $7135 \mathrm{eV}$ demonstrates more clearly the difference between $\mathrm{Fe}^{2+}$ and $\mathrm{Fe}^{3+}$ (Figure 4a,b). This shoulder is also clearly seen in the experimentally measured spectra and its height is closer to the one of $\mathrm{Fe}^{3+}$ (Figure 4a,b). The structural coordination environment (cisand trans-site) of the Fe octahedron seems to have little effect on the calculated spectra that agrees well with the previous EXAFS studies.

The oxidation state and the preferential occupational site of the substituted iron atoms were determined using the linear combination fit defined as in Eq. 2. The data can be fitted best as a linear combination ("Fit l") of $F e_{\text {Cis, }}^{2+}, \mathrm{Fe}_{\text {Trans }}^{2+}, \mathrm{Fe}_{\text {Cis }}^{3+}$ and $\mathrm{Fe}_{\text {Trans }}^{3+}$ (Table 1 and 2). The corresponding compounds of the fits agreed best within the margin of errors. The exclusive contribution of the calculated $\mathrm{Fe}_{\mathrm{Cis}}^{3+}$ spectrum in the linear combination fit to measured Milosmontmorillonite spectrum ensured that ferric iron is preferred in the bulk incorporation. As the XANES spectra of the SWy-montmorillonite is very similar to the Milos-montmorillonite (with a nearly identical shoulder at the right side of the first peak), the exclusive ferric iron contribution is expected. The differences can be seen in the post-edge region cannot be reproduced assuming random distribution of the iron atoms in the sample.

A "Fit 2" was also performed similarly to the EXAFS case when the total contributions of the $\mathrm{Fe}^{2+}$ and $\mathrm{Fe}^{3+}$ were kept the same but the contributions of the different occupational sites were equalized (Table 1 and 2) to test the contribution of the different occupational site. The comparison of the fitting quality (Table 1 and 2) and the fitted curves (Figure 4c-f) revealed that there were only small differences between the two fits. Therefore, the preferential occupation of cis- or trans-sites by $\mathrm{Fe}^{2+}$ and $\mathrm{Fe}^{3+}$ in montmorillonite could not be inferred from the XAFS spectra alone.

\subsection{Structural position of Fe in bulk montmorillonite}

The structural parameters of the relaxed structures from geometry optimization were compared with the measurement results to obtain information about the differences between the different structures (Table 3). The average $\mathrm{Fe}^{2+}-\mathrm{O}$ distances of $(2.13 \pm 0.03) \AA$ are longer than the $\mathrm{Fe}^{3+}-\mathrm{O}$ distances of $(2.03 \pm 0.03) \AA$. The calculated distances are nearly identical for the cis- and trans-sites. The $\mathrm{Fe}-\mathrm{Al}$ and $\mathrm{Fe}-\mathrm{Si}$ distances are identical for $\mathrm{Fe}^{2+}$ and $\mathrm{Fe}^{3+}$ (Table 3). Therefore, the Fe-O shell provides only a hint about the oxidation state, whereas any conclusions about the cis- or trans-occupation based on the structural data are highly speculative. 
354 Table 3. Structural parameters and energy difference of bulk montmorillonite with iron 355 incorporation derived from the $a b$ initio calculations and EXAFS measurements

\begin{tabular}{|c|c|c|c|c|c|c|c|}
\hline \multirow{2}{*}{\multicolumn{2}{|c|}{$\begin{array}{l}\text { Structural } \\
\text { parameters }\end{array}$}} & \multicolumn{2}{|c|}{$\mathrm{Fe}^{2+}$} & \multicolumn{2}{|c|}{$\mathrm{Fe}^{3+}$} & \multirow{3}{*}{$\begin{array}{c}\text { EXAFS } \\
\text { (Milos) } \\
\text { "Fit 1" } \\
6.0 \pm 0.1\end{array}$} & \multirow{2}{*}{$\begin{array}{c}\text { Measurement } \\
\text { (Milos) }\end{array}$} \\
\hline & & Cis & Trans & Cis & Trans & & \\
\hline \multirow{2}{*}{$\mathbf{F e}-\mathbf{O}_{\mathrm{All}^{\mathrm{a}}}$} & $C N[-]$ & $6.0 \pm 0.1$ & $6.0 \pm 0.1$ & $6.0 \pm 0.1$ & $6.0 \pm 0.1$ & & $5.8 \pm 0.4$ \\
\hline & $R[\AA]$ & $2.14 \pm 0.03$ & $2.12 \pm 0.03$ & $2.03 \pm 0.03$ & $2.02 \pm 0.03$ & $2.05 \pm 0.03$ & $2.01 \pm 0.01$ \\
\hline \multirow{2}{*}{$\mathbf{F e}-\mathbf{O}_{\mathbf{H}^{\mathrm{b}}}^{\mathrm{b}}$} & $C N[-]$ & $2.0 \pm 0.1$ & $2.0 \pm 0.1$ & $2.0 \pm 0.1$ & $2.0 \pm 0.1$ & $2.0 \pm 0.1$ & \\
\hline & $R[\AA]$ & $2.08 \pm 0.04$ & $2.10 \pm 0.04$ & $2.00 \pm 0.04$ & $2.01 \pm 0.04$ & $2.03 \pm 0.04$ & \\
\hline \multirow{2}{*}{$\mathbf{F e}-\mathbf{O}^{\mathrm{c}}$} & $C N[-]$ & $4.0 \pm 0.1$ & $4.0 \pm 0.1$ & $4.0 \pm 0.1$ & $4.0 \pm 0.1$ & $4.0 \pm 0.1$ & \\
\hline & $R[\AA]$ & $2.14 \pm 0.03$ & $2.13 \pm 0.03$ & $2.04 \pm 0.02$ & $2.03 \pm 0.02$ & $2.07 \pm 0.02$ & \\
\hline \multirow[t]{2}{*}{$\mathbf{F e}-\mathbf{A l}$} & $C N[-]$ & $3.0 \pm 0.1$ & $3.0 \pm 0.1$ & $3.0 \pm 0.1$ & $3.0 \pm 0.1$ & $3.0 \pm 0.1$ & $2.8 \pm 0.5$ \\
\hline & $R[\AA]$ & $3.04 \pm 0.03$ & $3.04 \pm 0.03$ & $3.07 \pm 0.03$ & $3.07 \pm 0.03$ & $3.06 \pm 0.03$ & $3.05 \pm 0.02$ \\
\hline \multirow[t]{2}{*}{$\mathbf{F e}-\mathbf{S i}$} & $C N[-]$ & $4.0 \pm 0.1$ & $4.0 \pm 0.1$ & $4.0 \pm 0.1$ & $4.0 \pm 0.1$ & $4.0 \pm 0.1$ & $3.8 \pm 0.6$ \\
\hline & $R[\AA]$ & $3.25 \pm 0.03$ & $3.23 \pm 0.03$ & $3.24 \pm 0.03$ & $3.22 \pm 0.03$ & $3.23 \pm 0.03$ & $3.25 \pm 0.03$ \\
\hline \multicolumn{2}{|c|}{$\begin{array}{c}\text { Energy difference } \\
{[\mathrm{kcal} / \mathrm{mol}]}\end{array}$} & \multicolumn{2}{|c|}{$0.0 \pm 0.5$} & \multicolumn{2}{|c|}{$0.0 \pm 0.5$} & - & - \\
\hline
\end{tabular}

356 The occupancy of the cis- and trans-sites can be evaluated based on the relative energies of Fe 357 substitution in the cis- and trans-octahedra. The calculations predict that for low Fe content 358 investigated in this study, the relative energies of iron (both $\mathrm{Fe}^{2+}$ and $\mathrm{Fe}^{3+}$ ) in cis- and trans359 sites are equal within the uncertainties of the calculations (Table 3). This means that iron is 360 randomly distributed between the cis- and trans-sites. The observation is consistent with the 361 very similar structural parameters obtained in the XAFS simulations.

362 A previous ab initio study showed the differences between ferrous and ferric iron bearing 363 smectites investigating their structural properties (local structure of iron, hydroxyl 364 orientations, vibration dynamics of $\mathrm{H}$ and $\mathrm{Si})^{59}$. Our calculated structural parameters showed 365 good agreement with the results of this study ${ }^{59}$ : the average $\mathrm{Fe}-\mathrm{O}$ bond lengths $(2.11 \AA$ and $3662.02 \AA$ ) agreed within the uncertainty and Fe substitutions did not affect the coordination 367 structures of the $\mathrm{Al}-\mathrm{O}$ and $\mathrm{Si}-\mathrm{O}$ polyhedral in neither studies ${ }^{59}$. 


\section{Implication of the theoretical study in the interpretation of XAFS}

This study demonstrates that the full XAFS spectra of natural montmorillonites can be obtained as a linear combination fit of theoretical ab initio XAFS spectra calculated based on ab initio MD trajectories for pure phases without any empirical adjustments of structural parameters such as bond distances or coordination. Performed linear combination analysis yields valuable information on the mechanism of structural incorporation of Fe in natural clay minerals. The comparison of two different theoretical approaches for XAS calculations (RSMS and DFT-LSDA) demonstrates that XANES calculations for elements with $3 d$ electrons largely depends on the used theory. The differences between predictions of the two methods are significant and influence the accuracy of the quantitative data analysis. The results of the linear combination fit of XANES spectra obtained based on the DFT-LSDA approach showed best agreement with the corresponding analysis of the EXAFS spectra. The quantitative analysis of both EXAFS and XANES spectra suggest that iron is predominantly present in bulk montmorillonite in $\mathrm{Fe}^{3+}$ oxidation state. The experimental spectra could be fitted equally well by assuming arbitrary contribution of Fe in cis- and trans-sites or imposing equal occupation of these sites. The energy calculations suggested that at low concentrations $\mathrm{Fe}^{2+}$ and $\mathrm{Fe}^{3+}$ are equally distributed between cis- or trans-sites.

An important step towards is the better understanding of the iron uptake mechanism in the determination of relevant edge surfaces of montmorillonite. Such information will be essential for understanding the mechanism of the probable oxidative uptake of iron $\left(\mathrm{Fe}^{2+}{ }_{\text {aq }}->\mathrm{Fe}^{3+}\right.$ surf $)$ by clay minerals ${ }^{9}$. In the best case, the comparison of the $a b$ initio based XAFS calculations and the measurements will result in the determination of the oxidation state of Fe in the bulk and at the surface. The results may give insight on whether the $\mathrm{Fe}^{2+}->\mathrm{Fe}^{3+}$ redox reaction occurs between the Fe atoms adsorbed on the surface and incorporated structurally into the bulk.

\section{Acknowledgements}

The research leading to these results has received funding from the Swiss National Foundation (SNF) through project number SNF-200021_156412 (2015-2018). The authors also acknowledge the financial support from Nationale Genossenschaft für die Lagerung radioaktiver Abfälle (NAGRA). The help of the staff of the beamline 11-2 at the SSRL is gratefully acknowledged. Use of the Stanford Synchrotron Radiation Lightsource, SLAC 
399 National Accelerator Laboratory is supported by the U.S. Department of Energy, Office of 400 Science, Office of Basic Energy Sciences under Contract No. DE-AC02-76SF00515. The 401 SSRL Structural Molecular Biology Program is supported by the DOE Office of Biological 402 and Environmental Research and by the National Institutes of Health, National Institute of 403 General Medical Sciences (including P41GM103393). The contents of this publication are 404 solely the responsibility of the authors and do not necessarily represent the official views of 405 NIGMS or NIH. The work was supported by a grant from the Swiss National Supercomputing 406 Centre (CSCS) under project ID "s620". The use of computer resources of the Merlin 4 407 Cluster, Paul Scherrer Institute is also gratefully acknowledged. The authors are grateful to 408 Dr. Enzo Curti for the critical discussion of the XANES results.

\section{References}

(1) Stucki, J. W.; Goodman B. A.; Schwertamann, U. Iron in soils and clay minerals. Springer Science \& Business Media, Dordrecht, Netherlands, 2012, vol. 217, pp. 1-3.

(2) Ilton, E. S.; Boily, J. F.; Buck, E. C.; Skomurski, F. N.; Rosso, K. M.; Cahill, C. L.; Bargar, J. R.; Felmy, A. R. Influence of dynamical conditions on the reduction of U(VI) at the magnetite-solution interface. Environ. Sci. Technol. 2010, 44, 170-176.

(3) Soltermann, D.; Fernandes, M. M.; Baeyens, B.; Miehé-Brendlé, J.; Dähn, R. Competitive Fe(II)-Zn(II) uptake on a synthetic montmorillonite. Environ. Sci. Technol. 2014, 48, 190-198.

(4) Leupin, O. X.; Birgersson, M.; Karnland, O.; Korkeakoski, P.; Sellin, P.; Mäder, U.; Wersin, P. Montmorillonite stability under near-field conditions. Technical Report 1412, National Cooperative for the Disposal of Radioactive Waste (NAGRA), Wettingen, Switzerland, 2014, pp. 37-38.

(5) Stucki, J. W.; Golden, D. C.; Roth, C. B. Effects of reduction and reoxidation of structural iron on the surface charge and dissolution of dioctahedral smectites. Clay. Clay. Miner. 1984, 32(5), 350-356.

(6) Hofstetter, T. B.; Schwarzenbach, R. P.; Haderlein, S. B. Reactivity of Fe(II) species associated with clay minerals. Environ. Sci. Technol. 2003, 37, 519-528. 
(7) Hofstetter, T. B.; Neumann, A.; Schwarzenbach, R. P. Reduction of nitroaromatic compounds by $\mathrm{Fe}(\mathrm{II})$ species associated with iron-rich smectites. Environ. Sci. Technol. 2006, 40, 235-242.

(8) Stucki, J. W.; Lee, K.; Zhang, L.; Larson, R. A. Effects of iron oxidation state on the surface and structural properties of smectites. Pure. Appl. Chem. 2002, 74 (11), 21452158.

(9) Soltermann, D.; Fernandes, M. M.; Baeyens, B.; Dähn, R.; Joshi, P. A.; Scheinost, A. C.; Gorski, C. A. Fe(II) uptake on natural montmorillonites. I. Macroscopic and spectroscopic characterization. Environ. Sci. Technol. 2014, 48, 8688-8697.

(10) Pfingsten, W.; Bradbury, M. H.; Baeyens, B. The influence of Fe(II) competition on the sorption and migration of $\mathrm{Ni}(\mathrm{II})$ in MX-80 bentonite. Appl. Geochem. 2014, 26, 1414 1422.

(11) Soltermann, D.; Baeyens, B.; Bradbury, M. H.; Fernandes, M. M. Fe(II) uptake on natural montmorillonites. II. Surface complexation modeling. Environ. Sci. Technol. 2014, 48, 8698-8705.

(12) Guggenheim, S.; Adams, J. M.; Bain, D. C.; Bergaya, F.; Brigatti, M. F.; Drits, V. A.; Formosso, M. L. L.; Galan, E., Kogure, T.; Stanjek, H. Summary of recommendations of nomenclature committees relevant to clay mineralogy: Report of the association internationale pour l'Etude des Argiles (AIPEA) nomenclature committee for 2006. Clay. Clay. Miner. 2006, 54 (6), 761-772.

(13) Tsipursky, S. I.; Drits, V. A. The distribution of octahedral cations in the 2:1 layers of dioctahedral smectites studied by oblique-texture electron diffraction. Clay. Miner. 1984, 19, 177-193.

(14) Cardile, C. M. Structural site occupation of iron within 2:1 dioctahedral phyllosilicates studied by57Fe Mössbauer spectroscopy. Hyperfine. Interact. 1988, 41(1), 767-770.

(15) Stucki, J. W. Properties and behaviour of iron in clay mineral in Handbook of Clay Science (editors: Bergaya, F.; Theng, B. K. G.; Lagaly, G.) 2006, pp. 424-430.

(16) Cardile, C. M.; Johnston, J. H. ${ }^{57} \mathrm{Fe}$ Mössbauer spectroscopy of montmorillonites: A new interpretation. Clay. Miner. 1986, 34(4), 307-313.

(17) Manceau A., Lanson B., Drits V. A., Chateigner D., Gates W. P., Wu J., Huo D., Stucki J. W. Oxidation-reduction mechanism of iron in dioctahedral smectites: I. Crystal chemistry of oxidized reference nontronites. Am. Mineral. 2000, 85, 133-152. 
(18) Tsipursky, S. I.; Drits, V. A. The distribution of octahedral cations in the 2:1 layers ofdioctahedral smectites studied by oblique-texture electron diffraction. Clay. Miner. 1984, 19, 177-193.

(19) Gorski, C. A.; Aeschbacher, M.; Soltermann, D.; Voegelin, A.; Baeyens, B.; Fernandes, M. M.; Hofstetter, T. B.; Sander, M. Redox properties of structural Fe in Clay Minerals. 1. Electrochemical quantification of electron-donating and -accepting capacities of smectites. Environ. Sci. Technol. 2012, 46, 9360-9368.

(20) Gorski, C. A.; Klüpfel, L.; Voegelin, A.; Sander, M.; Hofstetter, T. B. Redox properties of structural Fe in clay minerals. 2. Electrochemical and spectroscopic characterization of electron transfer irreversibility in ferruginous smectite, SWa-1. Environ. Sci. Technol. 2012, 46, 9369-9377.

(21) Gorski, C. A.; Klüpfel, L. E.; Voegelin, A.; Sander, M.; Hofstetter, T. B. Redox properties of structural Fe in clay minerals: 3. Relationships between smectite redox and structural properties. Environ. Sci. Technol. 2013, 47, 13477-13485.

(22) Soltermann, D.; Fernandes, M. M.; Baeyens, B.; Dähn, R.; Miehé-Brendlé, J.; Wehrli, B.; Bradbury, M. H. Fe(II) sorption on a synthetic montmorillonite. A combined macroscopic and spectroscopic study. Environ. Sci. Technol. 2013, 47, 6978-6986.

(23) Churakov, S. V.; Dähn, R. Zinc adsorption on clays inferred from atomistic simulations and EXAFS spectroscopy. Environ. Sci. Technol. 2012, 46, 5713-5719.

(24) Ladeira, A. C. Q.; Ciminelli, V. S. T.; Duarte, H. A.; Alves, M. C. M.; Ramos, A. Y. Mechanism of anion retention from EXAFS and density functional calculations: Arsenic (V) adsorbed on gibbsite. Geochim. Cosmochim. Ac. 2001, 65 (8), 1211-1217.

(25) Shermann, D. M.; Randall, S. R. Surface complexation of arsenic(V) to iron(III) (hydr)oxides: Structural mechanism from ab initio molecular geometries and EXAFS spectroscopy. Geochim. Cosmochim. Ac. 2003, 67 (22), 4223-4230.

(26) Tsutsui, Y.; Sugimoto, K.-i.; Wasada, H.; Inada, Y.; Funahashi, S. EXAFS and ab initio molecular orbital studies on the structure of solvated silver(I) ions. J. Phys. Chem. A. 1997, 101, 2900-2905.

(27) Bocharov, D.; Krack, M.; Kalinko, A.; Purans, J.; Rocca, F.; Ali, S. E.; Kuzmin, A. Ab initio molecular dynamics simulations of the Sc K-edge EXAFS of scandium triuoride. J. Phys. Conf. Ser. 2015, 712, 012009. 
(28) Bocharov, D.; Chollet, M.; Krack, M.; Bertsch, J.; Grolimund, D.; Martin, M.; Kuzmin, A.; Purans, J.; Kotomin, E. Interpretation of the U L3-edge EXAFS in uranium dioxide using molecular dynamics and density functional theory simulations. J. Phys. Conf. Ser. 2016, 712, 012091.

(29) Teo, B. K. EXAFS: Basic principles and data analysis. Springer 1986, vol. 9, pp. 21-23.

(30) Churakov, S. V. Ab initio study of sorption on pyrophyllite: Structure and acidity of the edge sites. J. Phys. Chem. B 2006, 110, 4135-4146.

(31) Churakov, S. V.; Kosakowski, G. An ab initio molecular dynamics study of hydronium complexation in Na-montmorillonite. Philos. Mag. 2010, 90 (17), 14-28.

(32) Krähenbühl, F.; Stöckli, H. F.; Brunner, F.; Kahr, G.; Müller-Vonmoos, M. Study of the water-bentonite system by vapour adsorption, immersion calorimetry and X-ray techniques: I. Micropore volumes and internal surface areas, following Dubinin's theory. Clay. Miner. 1987, 22, 1-9.

(33) Johnston, J. H.; Cardile, C. M. Iron substitution in montmorillonite, illite and glaucionite by ${ }^{57} \mathrm{Fe}$ Mössbauer spectroscopy. Clay. Clay. Miner. 1987, 35 (3), 170-176.

(34) CP2K developers group, http://www.cp2k.org (2000-2017)

(35) VandeVondele, J.; Krack, M.; Mohamed, F.; Parrinello, M.; Chassaing, T.; Hutter, J. QUICKSTEP: Fast and accurate density functional calculations using a mixed Gaussian and plane waves approach. Comput. Phys. Commun. 2005, 167, 103-128.

(36) Goedecker, S.; Teter, M.; Hutter, J. Separable dual-space Gaussian pseudopotentials. Phys. Rev. B 1996, 54 (3), 1703-1710.

(37) Krack, M. Pseudopotentials for $\mathrm{H}$ to $\mathrm{Kr}$ optimized for gradient-corrected exchangecorrelation functionals. Theor. Chem. Acc. 2005, 114, 145-152.

(38) VandeVondele, J.; Hutter, J. Gaussian basis sets for accurate calculations on molecular systems in gas and condensed phases. J. Chem. Phys. 2007, 127, 114105.

(39) Perdew, J. P.; Burke, K.; Ernzerhof, M. Generalized gradient approximation made simple. Phys. Rev. Lett. 1996, 77 (18), 3865-3868.

(40) Perdew, J. P.; Burke, K.; Ernzerhof, M. ERRATA: Generalized Gradient Approximation Made Simple [Phys. Rev. Lett. 77, 3865 (1996)]. Phys. Rev. Lett. 1997, 78 (7), 1396.

(41) Rollmann, G.; Rohrbach, A.; Entel, P.; Hafner, J. First-principles calculation of the structure and magnetic phases of hematite. Phys. Rev. B 2004, 69, 165107. 
(42) Liechtenstein, A. I.; Anisimov, V. I.; Zaanen, J. Density-functional theory and strong interactions: Orbital ordering in Mott-Hubbard insulators. Phys. Rev. B 1995, 52 (8), R5467-R5470.

(43) Dudarev, S. L.; Botton, G. A.; Savrasov, S. Y.; Humphreys, C. J.; Sutton, A. P. Electron-energy-loss spectra and the structural stability of nickel oxide: An LSDA+U study. Phys. Rev. B 1998, 57 (3), 1505-1509.

(44) Bussi, G.; Donadio, D.; Parrinello, M. Canonical sampling through velocity rescaling. $J$. Chem. Phys. 2007, 26, 014101.

(45) Ankudinov, A. L.; Ravel, B.; Rehr, J. J.; Conradson, S. D. Real-space multiplescattering calculation and interpretation of X-ray absorption near-edge structure. Phys. Rev. B 1998, 58 (12), 7565-7575.

(46) Ankudinov, A. L.; Nesvizhskii, A. I.; Rehr J. J. Dynamic screening effects in x-ray absorption spectra. Phys. Rev. B 1998, 67, 115120

(47) Ankudinov, A. L.; Rehr, J. J. Theory of solid-state contributions to the X-ray elastic scattering amplitude. Phys. Rev. B 2000, 62 (4), 2437-2445

(48) Rehr, J. J.; Ankudinov, A. Ravel B. User's Guide, FEFF v8.40. University of Washington, Seattle, United States, 2006.

(49) Bunau, O.; Joly, Y. Self-consistent aspects of X-ray absorption calculations. J. Phys.Condens. Mat. 2009, 21, 345501.

(50) Guda, S. A.; Guda, A. A.; Soldatov, M. A.; Lomachenko, K. A.; Bugaev, A, L.; Lamberti, C.; Gawelda, W.; Bressler, C.; Smolentsev, G.; Soldatov, A. V.; Joly, Y. Optimized finite difference method for the full-potential XANES simulations: Application to molecular adsorption geometries in MOFs and metal-ligand intersystem crossing transients. J. Chem. Theory. Comput. 2015, 11, 4512-4521.

(51) Amestoy, P. R.; Guermouche, A.; L'Excellent, J.-Y.; Pralet, S. Hybrid scheduling for the parallel solution of linear systems. Parallel. Comput. 2006, 32 (2), 136-156.

(52) Joly Y. FDMNES User's Guide, Grenoble, France, 2016, pp. 49-53.

(53) Vantelon, D.; Montarges-Pelletier, E.; Michot, L. J.; Briois, V.; Pelletier, M.; Thomas, F. Iron distribution in the octahedral sheet of dioctahedral smectites. An Fe K-edge Xray absorption spectroscopy study. Phys. Chem. Miner. 2003, 30, 44-53.

(54) Newville, M. IFFEFFIT: interactive XAFS analysis and FEFF fitting. J. Synchrotron. Radiat. 2001, 8, 322-324. 
(55) Ravel, B.; Newville, M. ATHENA, ARTEMIS, HEPHAESTUS: Data analysis for Xray absorption spectroscopy using IFEFFIT. J. Synchrotron. Radiat. 2005, 12, 537-541.

(56) Teo, B. K. EXAFS: Basic principles and data analysis. Springer 1986, vol. 9, pp. 114128.

(57) Koningsberger, D.C.; Prins, R. X-Ray Absorption: Principles, Applications, Techniques of EXAFS, SEXAFS and XANES. John Wiley \& Sons, New York, USA, 1988, Chapter 6, pp. 211-253.

(58) Schaefer, M. V.; Gorski, C. A.; Scherer, M. M. Spectroscopic evidence for interfacial $\mathrm{Fe}(\mathrm{II})-\mathrm{Fe}(\mathrm{III})$ electron transfer in a clay mineral. Environ. Sci. Technol. 2011, 45 (2), $540-545$.

(59) Liu, X.; Meijer, E. J.; Lu, X.; Wang, R. Ab initio molecular dynamics study of Fecontaining smectites. Clay. Clay. Miner. 2010, 58 (1), 89-96. 